\title{
Analysis of Power Loss of 20 kV Power Distribution
}

\author{
Dasman Dasman \\ Institut Teknologi Padang, Departement of Electrical Engineering, Padang, West Sumatra
}

\begin{abstract}
In the distribution of electrical energy from the plant to the consumer, there is a decrease in quality due to the loss of power (losses). These power losses are caused by a voltage drop across the line and subsequently producing a power loss on the line. This power loss can be classified into two types based on its line parameters, i.e., active power loss and reactive power loss. The line's active power loss generates losses of power/losses so that the active power reaches the load on the receiving end is always less than the productive power of the sender side. Power losses in the electrical system must exist and cannot be reduced to $0 \%$ (zero percent). According to SPLN No. 72 of 1987, the permitted distribution network's power loss should not be higher than $10 \%$. This paper investigates the magnitude of the voltage loss and the line active power losses on the $20 \mathrm{kV}$ distribution line. The calculation conducted through case study and simulation of Etap 12.6 program on an electrical power distribution system that is $20 \mathrm{kV}$ distribution line in PT. PLN (Persero) Rayon Muara Labuh. In the distribution line 20 $\mathrm{kV}$, there is IPP (Independent Power Plant) PLTMH PT SKE used to improve the stress conditions in Rayon Muara Labuh. Therefore the loss of power will be calculated in 3 terms, i.e., before and after IPP PT. SKE with $20 \mathrm{kV}$ distribution lines as well as on feeder load maintenance (as a repair action plan). The simulation results show the highest voltage drop and the highest power losses continue generated during IPP. PT SKE has not done synchronized with the distribution line of $20 \mathrm{kV}$ with a significant voltage drop of $1,533 \mathrm{kV}$ percentage of $7.93 \%$ and power loss of $777.528 \mathrm{kWh}$ percentage of $7.69 \%$.
\end{abstract}

\section{Introduction}

Given the importance of electrical energy for people's lives and for national development, a power system must be able to serve customers well both in terms of continuity and quality. However, in the distribution of electrical energy from the generator up to the consumer, a decline in quality due to the emergence of power losses (losses). The power loss caused by the voltage drop on the line and then produces power losses in the line. Drop voltage itself occurs from two components namely I. Rs is the voltage drop due to line resistance and I.Xs is the voltage drop due to line reactance. The voltage drop due to passage resistance will cause a loss of active power while the voltage drop due to line reactance will cause reactive power losses [1].

Power losses in the electrical system must exist and can not be reduced to $0 \%$ (zero percent). According to SPLN No. 72 of 1987, the permitted distribution network's power loss should not be greater than $10 \%$. This study was conducted to analyze the power losses account for a large line with a line voltage drop through a case study on the distribution lines distribution line (feeder) $20 \mathrm{kV}$ PT. PLN (Persero) Rayon Muara Labuh. In the $20 \mathrm{kV}$ distribution line, there are IPPs (Independent Power Plant) MHP PT
SKE used to improve voltage conditions in Muara Labuh Rayon. Therefore for the initial stages, the power loss will be analyzed in two conditions namely before IPP PT SKE interconnection and after IPP PT SKE interconnected with $20 \mathrm{kV}$ distribution line owned by PLN. While the method used is by the method of direct calculation (study formula) and by using the program Etap 12.6 [2]

After large power loss is obtained, then the prepared work plan and an action plan to reduce the power loss. One of the steps that can be done is to solve the load on 2 or more existing feeders. This stage is a stage- 3 in calculating the power loss of $20 \mathrm{kV}$ distribution line Rayon Muara Labuh [3-6].

\section{Review of The Literatures}

The distribution line is illustrated by an equivalent model by taking the circuit parameters on a per phase basis. Terminal voltage is described from one line to neutral, the current phase of the line so that the threephase distribution system is reduced to an equivalent single-phase distribution system. The distribution line model is used to calculate the voltage, current and power flow that is influenced by line length. The distribution line model is obtained by multiplying the impedance of the long unity line with the line length

\footnotetext{
${ }^{*}$ Corresponding author: dasman@gmail.com
} 


$$
\begin{aligned}
& Z=\left(r+f \omega L_{0}\right) l \\
& Z=R+j X \ldots \ldots \ldots
\end{aligned}
$$

Where $\mathrm{r}$ and $\mathrm{L}$ represent the resistance and the perphase inductance of the length, and 1 is the channel length The distribution channel model on a per phase basis is shown in fig. 1. and the voltage and current at the end of the shipping channel, and the voltage and current at the receiving end of the channel.

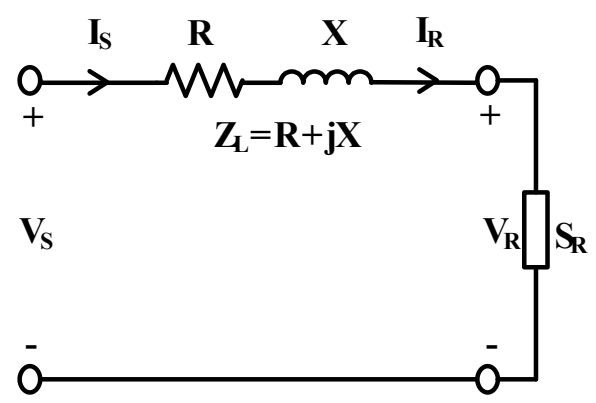

Fig. 1. Distribution Channel Model

If the three-phase apparent power is distributed to the load at the receiving end, the sender's end current is obtained through

$$
I_{S}=\frac{S_{S}(\mathrm{a} \phi)}{3 V_{S}}
$$

Where:

$\mathrm{S}_{\mathrm{S}(3 \phi)}=$ three-phase visible power at the sender side (MVA)

$\mathrm{Vs}=$ voltage sender side $(\mathrm{kV})$

Therefore, the circuit current distribution channel is a series connection which channel shunt capacitance is ignored, the current source end and the receiving end is the same,

$$
I_{S}=I_{R}
$$

Drop voltage (voltage drop) is the difference between the send voltage and the receive voltage due to impedance and channel current in the conductor. Drop channel voltage can be determined,

$$
\begin{aligned}
V_{Z} & =I_{S} . Z_{L} \ldots \ldots \ldots . . . \\
& =I_{S} .\left(R+j X_{L}\right) .
\end{aligned}
$$

Where :

$\mathrm{ZL}=$ channel impedance

In the calculation, the value of the channel reactance can be ignored so that the equation becomes:

$$
V_{Z}=I_{S} \cdot R
$$

The receiving-side voltage or the voltage reaching to the load is the receiving side voltage less the channel drop voltage,

$$
V_{R}=V_{S}-V_{Z}
$$

Based on channel equivalent circuit shown in Figure 1, and the description of equation (1) to (8) can be described phasor diagrams of current and voltage to the load with a lagging power angle (lagging) as shown in Figure 2.

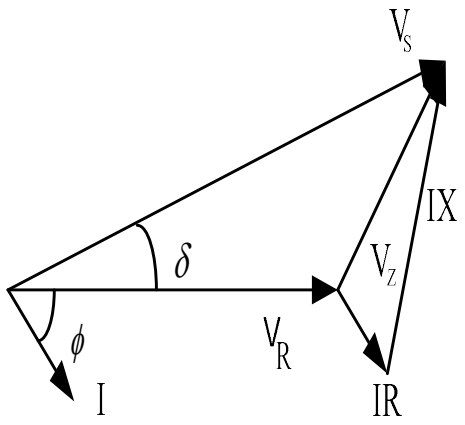

Fig. 2 Phasor Channel of Distribution Channel

with a large percentage value (\%) voltage drop is,

$$
\% \mathrm{~V}_{\text {rugi }}=\frac{V_{Z}}{V_{S}} X 100 \%
$$

Based on Figure 2, the channel power loss arises because of the channel resistance and reactance components in the form of active and reactive power losses. The current flowing on the channel will produce a visible loss of power channel,

$$
S_{Z(30)}=3 \cdot V_{Z} I_{S}{ }^{*}
$$

The visible power loss generated on the line consists of active power loss and reactive power loss written in the form of complex numbers in which the active power loss as real numbers and reactive power losses as imaginary numbers,

$$
S_{z(30)}=P_{z(3 \phi)}+j Q_{z(3 \phi)}
$$

Based on the phasor diagram of Figure 2.2, the active power loss per phase can be determined from the variable current, voltage and angle of the phase difference of the voltage drop and current of the channel,

$$
P_{z}=V_{z} I_{S} \cos \emptyset
$$

The phase difference angle between the voltage drop and the line current, cos is also called the power angle of the channel or power factor. 


\section{Result and Discussion}

From the single line diagram of distribution channel 20 $\mathrm{kV}$ Rayon Muara Labuh can be seen that distribution channel Rayon Muara Labuh has 3 pieces Exp. Feeder among others Exp. Feeder Muara Labuh, Exp. Feeder Lubuk Gadang and Exp. Feeder SKE. Besides Exp. Feeder there are also 5 pieces of Feeder services include Feeder Muara Labuh, Feeder City, Feeder Partners, Feeder Lubuk Malako, and Feeder Mark.

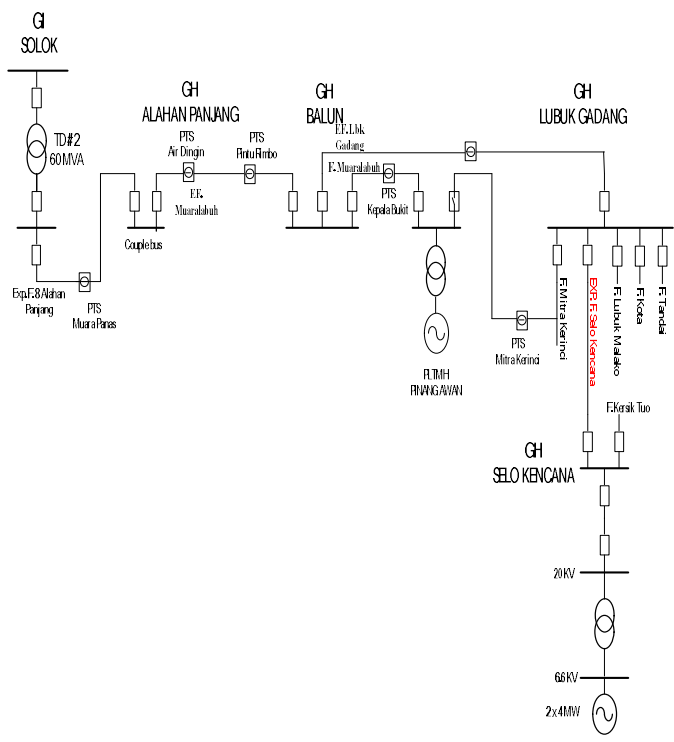

Fig. 3 Single Line Channel Distribution Diagram 20 kV Rayon Muara Labuh

Table 1 Network Length per Feeder

\begin{tabular}{|c|c|c|c|c|c|}
\hline \multirow{2}{*}{ NO. } & \multirow{2}{*}{$\begin{array}{c}\text { FEEDER } \\
\text { NAME }\end{array}$} & \multicolumn{4}{|c|}{ CONDUCTOR A3C (kms) } \\
\cline { 3 - 6 } & $\begin{array}{c}\mathbf{2 4 0} \\
\mathbf{m m}^{\mathbf{2}}\end{array}$ & $\begin{array}{c}\mathbf{1 5 0} \\
\mathbf{m m}^{\mathbf{2}}\end{array}$ & $\begin{array}{c}\mathbf{7 0} \\
\mathbf{m m}^{\mathbf{2}}\end{array}$ & $\begin{array}{c}\mathbf{3 5} \\
\mathbf{m m}^{\mathbf{2}}\end{array}$ \\
\hline 1 & $\begin{array}{c}\text { EXP. } \\
\text { FEEDER } \\
\text { MLBH }\end{array}$ & 0,000 & 27,117 & 20,684 & 4,300 \\
\hline 2 & $\begin{array}{c}\text { MUARA } \\
\text { LABUH }\end{array}$ & 0,000 & 0,000 & 43,146 & 0,637 \\
\hline 3 & $\begin{array}{c}\text { EXP. } \\
\text { FEEDER } \\
\text { LBGD }\end{array}$ & 0,000 & 44,900 & 0,000 & 0,000 \\
\hline
\end{tabular}

\begin{tabular}{|c|c|c|c|c|c|}
\hline 4 & $\begin{array}{c}\text { EXP. } \\
\text { FEEDER } \\
\text { SKE }\end{array}$ & 10,495 & 0,000 & 0,000 & 0,000 \\
\hline 5 & KOTA & 0,000 & 0,000 & 20,169 & 5,700 \\
\hline 6 & MITRA & 0,000 & 0,000 & 39,600 & 0,000 \\
\hline 7 & TANDAI & 0,000 & 29,700 & 11,769 & 0,000 \\
\hline 8 & $\begin{array}{c}\text { LUBUK } \\
\text { MALAKO }\end{array}$ & 1,100 & 66,200 & 12,500 & 0,000 \\
\hline \multicolumn{7}{|c|}{ Sum } & $\mathbf{1 1 , 5 9 5}$ & $\mathbf{1 6 7 , 9 1 7}$ & $\mathbf{1 4 7 , 8 6}$ & $\mathbf{8}, \mathbf{1 0 3 7}$ \\
\hline
\end{tabular}

Table 2 Impedance Conductor A3C By SPLN 641985

\begin{tabular}{|c|c|c|c|}
\hline $\begin{array}{c}\mathbf{a} \\
\left(\mathbf{m m}^{\mathbf{2}}\right)\end{array}$ & $\mathbf{r}(\boldsymbol{\Omega})$ & $\mathbf{j} \mathbf{X}(\boldsymbol{\Omega})$ & $\mathbf{Z}(\mathbf{\Omega}) \mathbf{\Theta}(\mathbf{0}$ \\
\hline 16 & 1,9550 & 0,40506 & $1,9965 \angle 11,70$ \\
\hline 25 & 1,1830 & 0,38966 & $1,2455 \angle 18,23$ \\
\hline 35 & 0,9217 & 0,379 & $1,0322 \angle 21,86$ \\
\hline 55 & 0,6650 & 0,37296 & $0,7624 \angle 29,28$ \\
\hline 70 & 0,4608 & 0,3572 & $0,5830<37,78$ \\
\hline 95 & 0,3550 & 0,38442 & $0,5232 \angle 47,28$ \\
\hline 110 & 0,2930 & 0,37729 & $0,4777 \angle 52,167$ \\
\hline 150 & 0,2250 & 0,38966 & $0,4499 \angle 59,997$ \\
\hline 185 & 0,1830 & 0,38442 & $0,4257 \angle 64,54$ \\
\hline 240 & 0,1370 & 0,35488 & $0,3804 \angle 68,89$ \\
\hline
\end{tabular}

The load data used in this calculation can be seen in table 3 .

Table 3 Feeder Load at Peak Load Time

\begin{tabular}{|c|c|c|}
\hline NO & FEEDER NAME & LOADS WBP (A) \\
\hline 1 & EXP. FEEDER MLBH & 18,0 \\
\hline 2 & MUARALABUH & 86,6 \\
\hline 3 & EXP. FEEDER LBGD & 152,3 \\
\hline 4 & EXP. FEEDER SKE & 283,6 \\
\hline 5 & KOTA & 46,3 \\
\hline 6 & MITRA & 34,0 \\
\hline 7 & TANDAI & 2,6 \\
\hline 8 & LUBUK MALAKO & 59,3 \\
\hline & JUMLAH & $\mathbf{6 8 2 , 7 0}$ \\
\hline
\end{tabular}

The data obtained during the research were analyzed using ETAP simulation. Starting from Single Line Diagram data, Rayon Muara Labuh Asset data, as well as Load Measurement data, then simulated using ETAP 12.6.

Network length data per Feeder is grouped by type and area of cross section. The data can be seen in table 1. Network length data are grouped per section in accordance with Feeder service area. The resistance value (r) and reactance $(\mathrm{X})$ of the carrier is obtained from the standard contained in SPLN 64 Year 1985. The data can be seen in Table 2 as follows: Manual calculations should be added to calculations when 20 $\mathrm{kV}$ PLN system has not been in sync with IPP PT. SKE. But it can not be done because it is constrained by the absence of load data. The steps performed in calculating the value of voltage drop and power loss are as follows: 
a. Calculates channel resistance value according to table data (1) and table (2).

b. Calculate the voltage drop value according to equation (7)

c. Calculate the value of power loss according to equation (12).

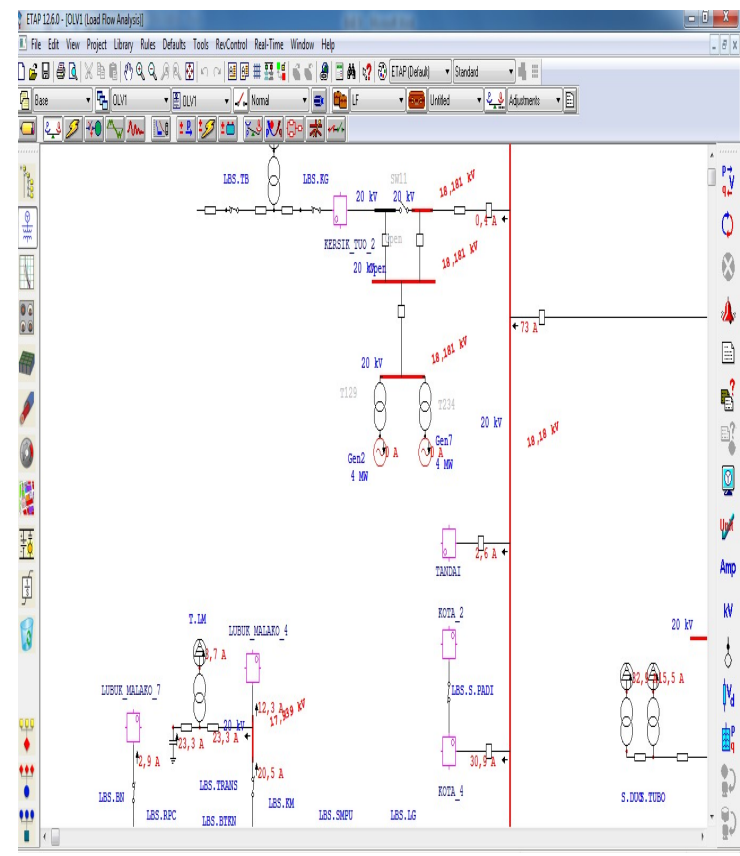

Fig. 4 Etap Simulation Before IPP PT. SKE Interconnection

From result of simulation Etap obtained value of voltage drop equal to $1,535 \mathrm{kV}$ with percentage of $7.93 \%$ and power loss value equal to $1079,9 \mathrm{~kW}$ with percentage of $7,69 \%$.

When the power loss is changed in units of electrical energy equivalent to:

$$
\begin{aligned}
\mathrm{E} & =\mathrm{P} . \mathrm{T} \\
& =1079.9 \mathrm{~kW} \times 24 \text { hours } \times 30 \text { days } \\
& =777.528 \mathrm{kWh}
\end{aligned}
$$

After the previous IPP PT. SKE is not connected to the $20 \mathrm{kV}$ distribution channel owned by PLN, then in this discussion IPP PT. SKE we connect with $20 \mathrm{kV}$ system so that icon T129 and T234 which was blurred, start seen clearly as in fig 4.

After the feeder load is broken, a new shrinkage difference is obtained. Stages performed to solve the feeder load equal to the stages when done manual calculations.

From the results of the simulation Etap obtained voltage drop value of $0.822 \mathrm{kV}$ with $4.10 \%$ percentage and power loss value of $514.4 \mathrm{~kW}$ with $4.20 \%$ percentage.

When the power loss is changed in units of electrical energy equivalent to:

$$
\begin{aligned}
\mathrm{E} & =\mathrm{P} . \mathrm{T} \\
& =514.4 \mathrm{~kW} \times 24 \text { hours x } 30 \text { days } \\
& =370.368 \mathrm{kWh}
\end{aligned}
$$

\section{Conclusions}

From the calculation that has been done, either manually or simulation, can be concluded as follows:

1. From the condition of IPP PT. SKE has not been interconnected with distribution channel $20 \mathrm{kV}$, for simulation calculation, obtained voltage drop equal to $1,533 \mathrm{kV}$ with percentage of $7.93 \%$ and power loss equal to $777.528 \mathrm{kWh}$ with percentage of $7,69 \%$.

2. Difference of power loss from manual calculation and simulation calculation, at condition 2 and 3, $1,305 \mathrm{kWh}$ with percentage $0.0001 \%$.

\section{References}

1. Kadir, A. Power Distribution and Utilities. Jakarta: Universitas Indonesia Press (2006)

2. SPLN No.72: Design Specification For Medium Voltage Network and Low Voltage Network, Jakarta, PT. PLN (Persero). (1987)

3. Akbar, A.A. Calculation of Power Shuts On Medium Voltage Distribution System of Air and Cable Channels. (2007).

4. Elisa Lubis,. Study of Loss Loss Energy Loss on Melon 20 KV Repeaters". (2008)

5. Muhdar, Isla. Juniarti and Suherman Yunus. "Drop Voltage Evaluation In Medium Voltage Network 20 KV Feeder Bojo PT. PLN (Persero) Rayon Mattirosi. (2013)

6. Riski, Aldi. The Influence of Adding Networks to Drop Voltage at SUTM 20 kV Grade Feeder Tuo Rayon Kersik Tuo Kerinci District. (2013) 